\title{
Copper versus the gonococcus in vivo
}

\author{
LESTER COHEN AND GLENNA THOMAS \\ University Hospital of Wales
}

The bactericidal activity of copper and its salts has been generally found to be of a low order in vitro by such authorities as Porter (1946) and Sprowls and Poe (1943). At the beginning of 1973 our attention was drawn to the fact that copper salts in certain concentrations had in fact been found to be toxic to gonococci.

Fiscina, Oster, Oster, and Swanson (1973), working at the Mount Sinai Medical School, New York, found that copper sulphate at a concentration of $1 \times 10^{-6} \mathrm{M}$ or greater is toxic to $1 \times 10^{7}$ to $1 \times 10^{8}$ gonococci per ml., $1 \times 10^{-5} \mathrm{M}$ destroying most viable organisms within approximately 30 minutes. Furthermore, they also found that a copper wire placed on gonococci plated out on agar caused inhibition of growth in a wide area around the wire. A copper loop placed on such a plate is shown in the Figure. The surrounding zone of inhibition can easily be seen. The inhibition of growth is caused by minute quantities of copper dissolved from the wire. It is of interest to note that Fiscina and her colleagues obtained little inhibition of growth of $E$. coli using copper salts at a concentration 10,000 times greater than that required to inhibit the gonococcus. They mention that the small amount of copper incorporated in some intrauterine contraceptive devices (IUDs) is slowly lost over a period of 2 years at the rate of about $1 \mu \mathrm{g}$. per day. Half of this soluble copper is absorbed through the uterine wall and the remainder is carried out in the uterine and cervical secretions. They calculated that the concentration of copper salts in these secretions would be at least $5 \times 10^{-6} \mathrm{M}$., a level well within the inhibitory range for the gonococcus.

At the present time all forms of treatment for gonorrhoea are therapeutic, although Singh, Cutler, and Utidjian (1972) have investigated the effect of twenty vaginal contraceptive preparations and seventeen other compounds in vitro and found that several products inhibited gonococcal growth. A suitable vaccine has yet to be produced, tested, and applied,

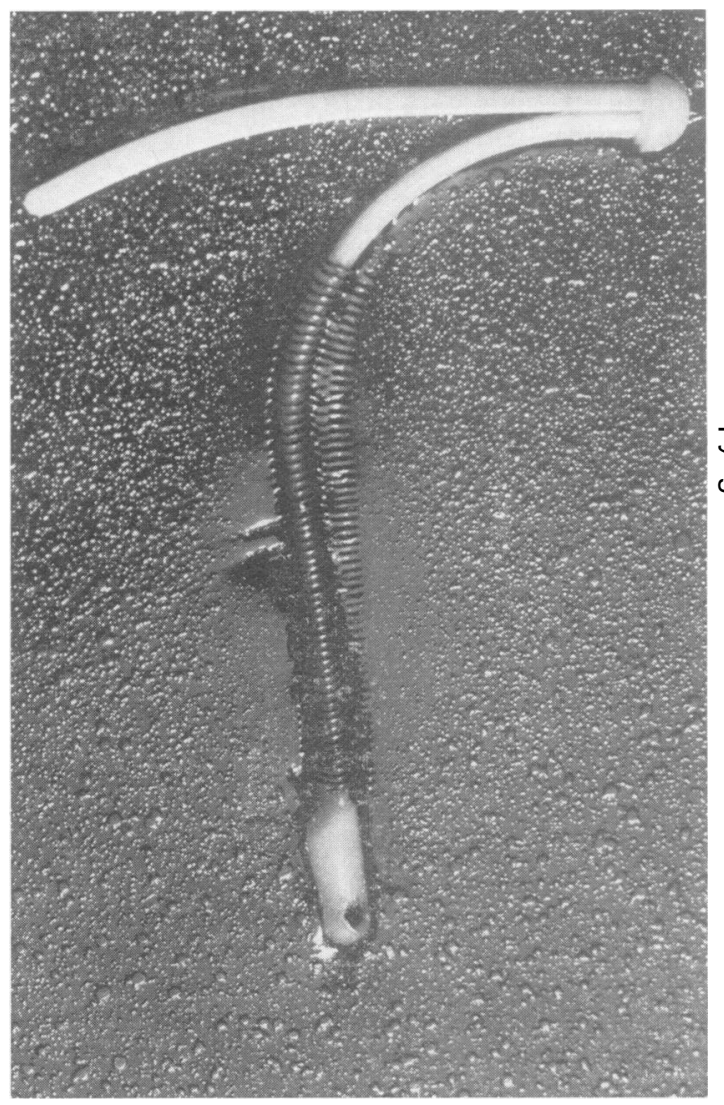

FIGURE Zone of inhibition of N. gonorrhoeae surrounding a copper-coil intrauterine device

with all the problems that this would involve both ethically and financially. If a copper-bound IUD was found to be gonococcocidal, it would certainly prove of considerable prophylactic value to the wearer.

It was obvious that an investigation into the possible prophylactic properties of the copper-bound IUD would have to be carried out epidemiologically. We should have to wait until a secondary female 
contact of a male proven to be suffering from gonococcal urethritis, in whom a copper-bound IUD had been inserted, came into our ken.

In the past year we have been fortunate enough to have had the opportunity of examining three such patients. In each case we were able to demonstrate positive cultures for gonococci in the male contact, examine the primary contact, and follow up adequately the female secondary contact wearing the necessary type of IUD.

\section{Case history}

As the epidemiological circumstances in the three cases were identical it is proposed to describe only one in detail.

A male patient aged 28 years attended complaining of dysuria and an urethral discharge of 4 days' duration. $\mathrm{He}$ admitted to a casual exposure 6 days previously. Intercourse took place vaginally and without the use of a sheath. The girl in question was stated to have been using an oral contraceptive. The man denied any previous infections and admitted to having had intercourse vaginally with his wife 3 days after exposure when he had already noted his urethral discharge. Gram-negative intracellular diplococci were seen in smears from both the urethral discharge and the urine centrifugate. Culture of the urethral discharge and urine on modified Thayer-Martin agar grew colonies which were oxidase-positive and fermented glucose only. $\mathrm{He}$ was treated with an intramuscular injection of $2 \mathrm{~g}$. spectinomycin. The sensitivities to five current antibiotics were tested in the laboratory. He was given contact slips for his primary and secondary contacts.

Two days later, the secondary contact (the patient's wife) attended. She was aged 27 and had four children and we were delighted to learn that a 'Graviguard' IUD had been inserted 6 months previously. She had no symptoms and on examination there was no evidence of urethral, vaginal, or cervical discharge. The cervical mucous plug was intact and through the external os could be seen the tail of the IUD. Smears and cultures were taken from the urethra, cervix, Bartholin's ducts, and rectum. Routine serological tests for syphilis and gonorrhoea proved negative. No diplococci were found in any of the smears and over the next 5 days no colonies of $N$. gonorrhoeae were grown. Smears and cultures were taken from the same sites at weekly intervals over the next 4 weeks and at the end of 6 weeks. All failed to show the presence of $N$. gonorrhoeae. 8 weeks after her first attendance she was again examined; she admitted to vaginal intercourse with her husband who had by this time been cleared of infection. Again, no Neisseria was found and the husband 1 week later was also found to be clear of infection.

The primary contact attended one day after the secondary contact. Routine investigations showed the presence of $N$. gonorrhoeae with the same sensitivity pattern as the organism isolated from the male. Treatment with $4 \mathrm{~g}$. intramuscular spectinomycin was successful.
Two other female secondary contacts who both used copper-bound IUDs have been investigated under exactly similar circumstances in the past year. Neither contracted a gonococcal infection.

\section{Discussion}

In order to demonstrate the protective value of the copper-bound IUD against the gonococcus in vivo, it is necessary to examine a woman with such a device in-situ who has beyond reasonable doubt had sexual intercourse by the vaginal route with a male partner proven to be suffering at the time from urethral gonorrhoea. One need hardly state the obvious fact that such a set of circumstances is hard to come by.

That we have been able to glean only three cases in the past year proves nothing, but it does indicate that the investigations of Fiscina and others (1973) are worth pursuing. We have examined four other women in the past year who have been using a copper-coil IUD. None of these had gonorrhoea, but then none of them was a contact of a male with gonorrhoea. The four presented with vaginal discharge. Three were found to have candidal vaginitis and the fourth trichomoniasis. We have so far not examined a woman wearing a copper-coil IUD who had cervical gonorrhoea.

There may be a case for applying a copper coil to a portion of all IUDs, if it can be shown conclusively that copper so used has a gonococcocidal effect. The safety and efficacy of the copper-coil loop has been shown by Tatum (1973) to be equal to other types of IUD provided it is inserted properly. The staff of a family planning clinic with close links to a special treatment centre might be in the best position to carry out an epidemiological investigation if they could be persuaded to insert only copper-bearing loops for a period of one year. It would certainly be worth while for venereologists and gynaecologists to pay special attention to any woman wearing a copper-bound IUD who might have been exposed to a gonococcal infection.

\section{Summary}

Three women with a copper-bound intrauterine contraceptive device who had been exposed to a proven gonococcal infection were investigated. None was found to have contracted a gonococcal infection.

I should like to thank Dr. R. A. Holman, Consultant Clinical Bacteriologist at the University Hospital of Wales, for drawing my attention to the original work and for providing the photograph. 


\section{References}

Fiscina, B., Oster, G. K., Oster, G., and Swanson, J. (1973) Amer. f. Obstet. Gynec., 116, 86

PORTER, J. R. (1946) 'Bacterial Chemistry and Physiology'. Wiley, New York

Singh, B., CUTleR, J. C., and Utidjian, H.M.D. (1972) Brit. f. vener. Dis., 48, 57

SPROWLs, J. B., and POE, D. F. (1943) f. Amer. pharm. Ass., 32, 41
Tatum, H. J. (1973) Amer. f. Obstet. Gynec., 117, 602

Rapport entre le cuivre et le gonocoque in vivo

\section{SOMMAIRE}

On a étudié trois femmes porteuses d'un dispositif contraceptif constitué par un ressort intra-utérin en cuivre et qui s'étaient trouvé exposées à une infection gonococcique prouvée. Aucune n'a été infectée de gonococcie. 